\title{
PATHOLOGY AND TREATMENT OF NON-CICATRICIAL ENTROPION BY THE METHOD PROPOSED BY WIES*
}

BY

\author{
O. O. F. FFOOKS \\ Royal Infirmary, Sheffield
}

AcCording to Kettesy (1948), non-cicatricial or senile entropion is the direct result of a migration and accumulation of orbicularis fibres at the lid margin. The contraction of the orbicularis which follows causes excessive pressure on the upper margin of the eyelid, the mechanics of the lid musculature are altered, and entropion results.

As stated by Kettesy (1948): "The normal distribution of orbicularis is maintained by connective tissue branching off between bundles"; in senility there is a slackening of this palpebral connective tissue, allowing the migration of muscle fibres, whereas in the young adult the pretarsal muscle fibres are firmly attached to the tarsal plate (Jones, 1960).

Most authors agree on the importance of senile degenerative processes in the eyelid in the aetiology of entropion. These processes include senile atrophy of orbital fat with relative enophthalmos, loss of elasticity of skin, degenerative flaccidity of the tarsus (Kirby, 1952), relaxation of inferior ligaments (Butler, 1948), and slackening of the whole palpebral connective tissue (Kettesy, 1948; McFarlane, 1956).

But, as Kettesy (1948) states, these are preliminary conditions. It is the accumulation of orbicularis fibres along the lid margin that causes entropion and surgical procedures must be designed to prevent it.

Non-cicatricial entropion of the upper eyelid is rare, because the insertions of the levator palpebrae into the skin form a more permanent anchor for the orbicularis. This effect is weakest at the outer margin, and one case of noncicatricial entropion of the outer third of the upper lid is included in this series.

The operation proposed by Wies (1954) is designed to place a barrier in front of the tarsal plate and thus to prevent the free movement of the orbicularis over it; if this movement is accepted as the primary cause of senile entropion, the excision of skin and orbicularis, or of wedges of tarsal plate, is unnecessary.

Wies's operation, as originally described, produces over-correction in a proportion of cases (Wies, 1954; McFarlane, 1956; Hill and Witzell, 1956); Wies incises the whole length of the tarsal plate, but, as the purpose of the operation is only to create a vertical barrier to the horizontally-acting muscle fibres, a more local incision should be sufficient. With the present technique, which is only slightly modified from Wies's original procedure, immediate cure results and over-correction does not occur.

* Received for publication May 9, 1960. 
The operation is extremely simple to perform and takes only a few minutes; it is performed as a routine primary procedure on all non-cicatricial cases of entropion and on all recurrent cases.

\section{Technique}

A large meibomian cyst clamp is placed over the central area of the lower lid, the footplate being placed in the lower fornix and the long axis about $3 \mathrm{~mm}$. below the lid margin.

A horizontal incision is made with a Bard Parker knife (No. 15 blade) 3 to $4 \mathrm{~mm}$. below the lid margin, cutting through all structures (skin, muscle, and tarsal plate) for the length of the long axis of the clamp. As emphasized by McFarlane (1956), the incision should be apparently slightly sloping towards the lid margin, otherwise the tarsal plate may not be included in the inferior lip of the wound. The length of the incision is about one-third of the length of the tarsal plate.

With the clamp still in place, two double-armed 12-mm. 3.0 U.S.P. sutures are placed through the tarsal plate in the inferior lip of the wound, entering from the conjunctival surface. If the tarsal plate is not incised with the first incision, the sutures are placed through the conjunctiva. These sutures are inserted through the skin of the upper lip of the wound just below the lid margin, care being taken to keep them parallel. They are pulled up but not tied, to make sure that the lower lip of the tarsal plate rides over the upper portion.

The skin incision is closed with interrupted 5-0 sutures, the clamp is released, and the deep sutures are tied firmly. Rubber strips are unnecessary.

Very little bleeding occurs, a bandage is not required, and all sutures are removed after 5 days. There may be a slight tendency to ectropion, but this disappears after the first day or two.

\section{Results}

35 operations were performed on 31 patients with non-cicatricial entropion by the Wies method during the period April, 1958, to September, 1959, and these were reviewed in April, 1960. One operation was for non-cicatricial entropion of the upper lid (outer third).

In 25 cases there has been no recurrence after one year or longer, and in eight there has been no recurrence for from 6 to 12 months.

In two cases there was a recurrence, one after one year and the other after 6 months. The operation was repeated and one patient has remained free from recurrence for 6 months and the other for one year.

The operation was performed as a primary procedure in 26 cases and for recurrent entropion in nine cases.

There were no cases of over-correction.

\section{Discussion}

Ziegler's cautery puncture and skin and muscle operations provide only a temporary cure in a large percentage of cases, although skin and muscle procedures that include deeper structures in the lid sutures are of a more permanent nature. 
The development of fibrous tissue between the tarsal plate and skin produces a relief of entropion by preventing the free movement of the orbicularis. As the fibrous scar recedes, the tendency to entropion increases.

Transplantation of skin (Lebensohn, 1953) and excision of tarsal wedges (Butler, 1948; Fox, 1951) attack part of the degenerative process and not the cause of the entropion, unless a weakened tarsus is considered to be the primary cause of entropion.

Wheeler's operation or one of its modifications has usually been considered the most satisfactory treatment for non-cicatricial entropion, but recurrences and over-correction are not infrequent (McFarlane, 1956; Hill and Witzell, 1956). No doubt these results depend partially on technique, but while the procedure attempts to re-establish lid pressure on the inferior part of the tarsal plate, it probably acts mainly by affecting the movement of the orbicularis. As it is not designed primarily for the latter procedure, it cannot be wholly successful.

The Hotz-Wheeler modification suggested by Hill and Witzell (1958) and also that of Jones (1960) may be more successful, but they seem to be unnecessarily complicated.

\section{Conclusions}

It is agreed that the cause of senile entropion is the free movement of the orbicularis over the tarsal plate which occurs as a consequence of the normal senile degenerative processes, the two most important being atrophy of the palpebral connective tissue and a weakened tarsal plate.

The Wies operation, designed to prevent this movement, seems to be simple and effective (Wies, 1954, 1955; McFarlane, 1956).

Over-correction, by the method used, does not occur. Recurrence, which is rare, is probably due to faulty technique.

\section{Summary}

The pathology of entropion is discussed. A slight modification of the Wies operation is described using a smaller incision. The results in 35 cases of non-cicatricial entropion are reviewed.

My thanks are due to Mr. A. B. Nutt, M.Sc., F.R.C.S., for permission to use his cases and for his encouragement in preparing this paper.

\section{REFERENCES}

Butler, J. B. V. (1948). Arch. Ophthal. (Chicago), 40, 665.

Fox, S. A. (1951), A.M.A. Arch. Ophthal., 46, 424.

Hill, J. C., and WrTzell, S. H. (1956). Trans. Canad. ophthal. Soc., 8, 69.

JONES, L. T. (1960). Amer. J. Ophthal., 49, 29.

KETTESY, A. (1948). Brit. J. Ophthal., 32, 311.

KIRBY, D. B. (1953). Trans. Amer. ophthal. Soc., 1952, 50, 359.

LEBENSOHN, J. E. (1953). Amer. J. Ophthal., 36, 504.

MCFARlane, D. C. (1956). Ibid., 41, 657.

WIES, F. A. (1954). J. int. Coll. Surg., 21, 758.

(1955). Trans. Amer. Acad. Ophthal. Otolaryng., 59, 503. 